\title{
As recomendações da Wonca para a saúde das populações rurais
}

Leonardo Vieira Targa. Universidade de Caxias do Sul (UCS). Ivtarga@ucs.br

Nilson Massakazu Ando. Secretaria Municipal de Saúde de Manaus (SEMSA). nilsonando@yahoo.com

André Luiz da Silva. Prefeitura Municipal de Eldorado do Sul/RS. PUCRS - Grupo de Pesquisa Redes, Identidade e Subjetividade - REDIS.

barmitzvar@yahoo.com.br

Rodrigo Pinheiro Silveira. Universidade Federal do Acre (UFAC). ropsilv@uol.com.br

Magda Almeida. Universidade de Fortaleza (UNIFOR). magnhets@gmail.com

Ricardo César Garcia Amaral Filho. Universidade do Estado do Amazonas (UEA).amaral.mfc@gmail.com

Mônica Correia Lima. Prefeitura Municipal de Cajati (SP). monicalima@usp.br

Leonardo Cançado Monteiro Savassi. Universidade Federal de Ouro Preto (UFOP). leosavassi@gmail.com

Dijon Hosana Souza Silva. Secretaria Municipal de Saúde de Jussari, Bahia. dijonhosana@hotmail.com

Thereza Cristina Gomes Horta. Prefeitura Municipal de Brumadinho (MG). thehorta@gmail.com

A Associação Mundial de Médicos de Família, através do seu grupo de trabalho de saúde rural, vem desenvolvendo açôes, participando de projetos e realizando recomendaçóes relacionados a diversos temas ligados à saúde rural. O Grupo de Trabalho em Medicina Rural da Sociedade Brasileira de Medicina de Família e Comunidade traduz para a língua portuguesa, neste número, os principais documentos que devem servir como referência para a construção de políticas e práticas nesta área. Abaixo um breve resumo dos artigos que se encontram neste volume.

O documento Política de Qualidade e Eficácia dos Cuidados de Saúde Rural ${ }^{1}$ é, na palavra do Grupo de Trabalho em Medicina Rural da Wonca, um esforço para estruturar o desenvolvimento de metas e avaliaçóes da qualidade e efetividade da prática da Medicina Rural, na busca dos objetivos de "Saúde para todos os povos" (OMS) e "Saúde para todas as Populaçóes Rurais em 2020"2.

Define-se a saúde rural como a interação necessária e a conectividade da pessoa rural com sua família e comunidade, alertando sobre o menor acesso das comunidades rurais do mundo a cuidados de saúde, pior estado e desfechos de saúde comparados com comunidades urbanas e afirma que as avaliaçôes de qualidade e efetividade do cuidado não estão disponíveis nem são dirigidos ou aplicados à realidade rural. $\mathrm{O}$ objetivo do documento é sugerir parâmetros que levem em conta estas especificidades.

Prover cuidados de saúde efetivos e de alta qualidade em um contexto de ruralidade é um desafio para qualquer nação, pois a saúde fundamenta-se em determinantes amplos, demandando cooperação multidimensional da comunidade nos aspectos ambientais, econômicos, disponibilidade de recursos, educação e cuidados de saúde, respeitando particularidades de algumas populaçóes como as indígenas, as minorias e as comunidades rurais isoladas para se atingir um status de saúde desejável.

A política apresentada neste documento se volta para esses aspectos e busca corrigir estas lacunas ao apresentar critérios e iniciativas que resultem na melhora da qualidade de vida dessas comunidades e permitam a mensuração da qualidade e 
da efetividade do cuidado à saúde. Identificam-se onze deles: o contexto rural, o estado de saúde rural, os desfechos em saúde rural, os serviços de saúde rural, a força de trabalho rural, a educação e o treinamento desta força de trabalho, a Infraestrutura rural e a tecnologia de informação, a pesquisa em saúde rural, o financiamento da saúde rural, a organização da saúde rural e a satisfação do consumidor de saúde rural. Para cada um dos parâmetros identificados, são discutidos a meta e o enquadramento e são feitos comentários pertinentes ao seu significado e importância no contexto.

Para o futuro, o documento reforça a Declaraçáo de Durban² que preconiza a "Saúde para Todos os Povos Rurais" e afirma ser imperativo usar metas e medidas de qualidade e efetividade dos cuidados de saúde rural no desenvolvimento de cuidados rurais de qualidade e eficácia.

O Manifesto de Melbourne $e^{3}$, adotado na 5 a. Conferência Mundial de Saúde Rural da Wonca, tem como foco a migração internacional de profissionais de saúde enquanto fator produtor de desigualdade entre sistemas de saúde. Este tema, que também já figurou como central em discussōes e documentos da Organização Mundial da Saúde , assume especial importância nos países mais pobres com consequências para a saúde de suas populaçóes.

O Manifesto, a partir de uma análise que busca equilibrar os direitos individuais com as necessidades das comunidades, propóe a formação de um código internacional de ética neste tópico. Visto que a migração nem sempre é danosa, sendo desejável em algumas situaçóes, sugere que: a) cada país que recebe profissionais de outros lugares examine sua situação e revise suas estratégias de recrutamento; b) países que experimentam perdas destes recursos humanos estudem as causas e reformulem suas políticas de formação, criação de oportunidades para retenção destes profissionais. Reconhece, além disso, a grande desigualdade de forças na competição entre os diferentes países em oferecer condiçóes atraentes de trabalho.

O Documento Política para Médicas de Família em Áreas Rurais ${ }^{5}$ foi elaborado por um grupo de médicos e alunos de medicina após extensa pesquisa em países desenvolvidos com o objetivo de apresentar propostas no intuito de dar suporte à mulher trabalhadora em áreas rurais e remotas em sua prática de medicina de família, aumentar o número de mulheres médicas nessas áreas e assegurar a equidade do desenvolvimento de políticas e programas que afetem a força de trabalho na medicina rural relacionados às médicas.

Aponta o documento que, muito embora a força de trabalho da mulher médica tenha aumentado nos últimos anos, ainda há um grande espaço para a inserção desse profissional em áreas rurais e remotas. A presença da mulher médica na liderança de instituiçóes para profissionais rurais, em eventos da categoria, pesquisa científica e publicaçóes foi apontada como essencial para a equidade do trabalho médico nestas regiôes. Sendo a mulher médica, um profissional com características de trabalho diferentes dos médicos homens, é importante o estímulo à formação, qualificação, educação permanente e fixação das médicas nessas áreas.

A Política para a Formaçáo para a Medicina de Família Rural ${ }^{6}$ apresenta consideraçôes e estratégias para o desenvolvimento de práticas de ensino para a graduação e pós-graduação de medicina, em cenários rurais, tendo em vista o aprimoramento da qualidade da prestação de serviços de saúde nestes locais. As orientaçôes do documento baseiam-se na necessidade global de incrementar o número de médicos qualificados com atuação em áreas rurais e remotas.

Prática médica rural é definida como a atividade médica executada fora de áreas urbanas, para a qual são necessárias competências mais diversificadas, incluindo as áreas de obstetrícia, cirurgia, anestesia e medicina de emergência.

Embora o foco principal do documento sejam programas de formação e preparação de graduados, iniciando no nível de pré-graduação e continuando com a educação médica através de cursos de formação profissional com treinamento vocacional específico, a intenção é contextualizar uma política de recrutamento e retenção de médicos na prática rural.

O texto explora as possíveis soluçôes para a dificuldade de retenção de profissionais e estudantes nas áreas rurais, concomitante à abordagem dos mitos e fatos que desestimulam a prática profissional nestes locais, como isolamento profissional, a crença em uma prática de menor padráo técnico, a falta de acesso imediato às instalaçóes de alta tecnologia e especialistas, entre outros.

O Documento de Compostela ${ }^{7}$, elaborado por médicos de família e comunidade participantes da 6a Conferência Mundial de Saúde Rural, trata de um dos maiores desafios da atualidade: a redução das iniquidades no tocante à questão do HIV/ AIDS de um modo global. Os autores reconhecem o caráter pandêmico e consolidado do vírus HIV em todo o mundo, em especial nos países em desenvolvimento, com aumento progressivo do número de infectados. Dentre questóes relevantes como envolvimento de instituições e profissionais e mobilização global, eles tratam do aspecto da interdisciplinaridade, já que se trata de uma questão de saúde em nível global e envolve determinantes biopsicossociais, econômicos, educacionais e de políticas públicas. 
A Declaraçáo de Kuching para Ação ${ }^{8}$, aprovada no $6^{\circ}$ Congresso Mundial de Saúde Rural, pontua a problemática e as especificidades da saúde dos povos indígenas e fornece recomendaçóes gerais para profissionais e gestores que trabalham na área. O documento reforça a definição de povos indígenas, trata a saúde como direito humano e defende o direito à autodeterminação e ao autogoverno. É congruente com a necessidade de atenção diferenciada e controle social, ressaltando que os povos indígenas devem participar da formulação, execução e avaliação das políticas públicas de atenção e de formação na área da saúde indígena. A cultura e a língua diferenciadas são colocadas de maneira central na organização dos serviços, sendo determinante o desenvolvimento da competência cultural por parte dos profissionais de saúde. A Declaração é finalizada com a recomendação de sua utilização na íntegra pelos Governos e pelas Nações Unidas.

O Grupo de Trabalho sobre Formação da Prática Rural da Wonca define Telessaúde como sendo a prestação de serviços de saúde à distância, tendo na Tecnologia da Informação e Comunicação um potencial considerável para que haja impactos positivos ou negativos sobre o acesso à prestaçáo dos serviços de saúde rural.

Sua declaração relacionada ao tema ${ }^{9}$ proporciona aos participantes, financiadores e planejadores dos serviços de saúde rural, orientaçôes para a introdução e o uso da Tecnologia da Informação e Comunicação nas comunidades rurais. Tendo como objetivo, fornecer diretrizes que garantam a gama de tecnologias consideradas apropriadas para as necessidades dos cuidados de saúde e serviços locais, sendo levados em consideração os contextos cultural e social em que os serviços serão introduzidos.

Entretanto, não há garantias de que a introdução de serviços de tecnologia da informação e comunicação será, automaticamente, um benefício para os trabalhadores de saúde rurais e as comunidades. No entanto, é possível, com um planejamento cuidadoso, maximizar o potencial dos serviços de tecnologia da informação e comunicação bem sucedidos e sustentáveis para as comunidades rurais.

Finalmente, afirma que os serviços de tecnologia da informação e comunicação nunca devem ser destinados a substituir a prestação de serviços direto em nível local, por profissionais de saúde devidamente treinados e apoiados. Pelo contrário, a tecnologia da informação e comunicação deve ser um complemento valioso para o suporte do padrão de atendimento que é oferecido para as pessoas que vivem nas comunidades rurais do mundo.

\section{Referências}

1. Wonca Working Party on Rural Practice. Policy on Quality and Effectiveness of Rural Health Care. Traralgon: Monash University School of Rural Health; 2002.

2. Wonca Working Party on Rural Practice. Durban Declaration; 2nd World Rural Health Congress; 1997, Durban South Africa. Wonca; 1997.

3. Wonca Working Party on Rural Practice. A Code of Practice for the International Recruitment of Health Care Professionals: the Melbourne Manifesto; 5th Wonca World Rural Health Conference; 2002, Melbourne, Australia. Wonca; 2002.

4. World Health Organization - WHO. The WHO Global CODE of Practice on the International Recruitment of Health Personnel. Implementation by the Secretatariat. Geneva: WHO; 2010.

5. Wonca Working Party on Rural Practice. Policy on Female Family Physicians in Rural Practice. Traralgon: Monash University School of Rural Health; 2002.

6. Wonca Working Party on Rural Practice. Política para a Formação para a Medicina de Família Rural. Wonca; 1995.

7. Wonca Working Party on Rural Practice. HIV/AIDS: O documento de Santiago de Compostela; 6 a Conferência Mundial de Saúde Rural da WONCA; 2003, Santiago de Compostela, Espanha. Wonca; 2003.

8. Wonca Working Party on Rural Practice. The Health of Indigenous Peoples: the Kuching Statement; 3rd World Rural Health Congress Kuching; 1999, Malaysia. Wonca; 1999.

9. Wonca Rural Information Technology Exchange - WRITE. Policy on Using Information Technology to Improve Rural Health Care. Traralgon: Monash University School of Rural Health; 1998. 